\title{
White Paper: Radiological Curriculum for Under- graduate Medical Education in Germany
}

\section{White Paper: Curriculum Radiologie für das Studium der Humanmedizin in Deutschland}

\begin{abstract}
Autoren (alphabetisch)
B. Ertl-Wagner ${ }^{1}$, J. Barkhausen², A. H. Mahnken ${ }^{3}$, H. J. Mentzel ${ }^{4}$, M. Uder ${ }^{5}$, J. Weidemann ${ }^{6}$, P. Stumpp

German Association of Chairmen G. Adam, G. Antoch, J. Barkhausen, M. Beer, T. Bley, A. Bücker, C. Düber, M. Forsting, B. Hamm, K. Hauenstein, in Academic Radiology (KLR) W. Heindel, N. Hosten, O. Jansen, T. Kahn, H. U. Kauczor, G. Krombach, C. Kuhl, M. Langer, M. Laniado, J. Lotz, A. Mahnken, D. Maintz, K. Nikolaou, M. Reiser, J. Ricke, E. Rummeny, H. Schild, S. Schönberg, R. P. Spielmann, C. Stroszczynski, U. Teichgräber, M. Uder, T. J. Vogl, F. Wacker
\end{abstract}

German Roentgen Society (DRG) D. Vorwerk, N. Hosten, S. Schönberg, F. Anton, S. Neumann, S. Lohwasser*,

Affiliations

Affiliation addresses are listed at the end of the article.

Key words

- medical education

- undergraduate teaching

- curriculum

competence-based learning

- radiological teaching received 9.6.2016

accepted $\quad 18.8 .2016$

Bibliography

Dol http://dx.doi.org/

10.1055/s-0042-116026

Published online: 2016

Fortschr Röntgenstr 2016; 188:

1017-1023 (c) Georg Thieme

Verlag KG Stuttgart · New York

ISSN 1438-9029

\section{Correspondence}

\section{Prof. Birgit Ertl-Wagner}

Institute of Clinical Radiology,

Ludwig Maximilians University -

Großhadern Campus

Marchioninistr. 15

81377 Munich

Germany

Tel.: ++ 49/89/440073250

Fax: ++49/89/440078822

Birgit.Ertl-Wagner@med.Imu.de

\section{Abstract \\ $\nabla$}

Purpose: Radiology represents a highly relevant part of undergraduate medical education from preclinical studies to subinternship training. It is therefore important to establish a content base for teaching radiology in German Medical Faculties.

Materials and Methods: The German Society of Radiology (DRG) developed a model curriculum for radiological teaching at German medical universities, which is presented in this article. There is also a European model curriculum for undergraduate teaching (U-level curriculum of the European Society of Radiology). In a modular concept, the students shall learn important radiological core principles in the realms of knowledge, skills and competences as well as core scientific competences in the imaging sciences.

Results: The curriculum is divided into two modules. Module 1 includes principles of radiation biology, radiation protection and imaging technology, imaging anatomy as well as the risks and side effects of radiological methods, procedures and contrast media. This module is modality-oriented. Module 2 comprises radiological diagnostic decision-making and imaging-based interventional techniques for various disease entities. This module is organ system-oriented.

Conclusion: The curriculum is meant as a living document to be amended and revised at regular intervals. The curriculum can be used as a basis for individual curricular development at German Medical Faculties. It can be integrated into traditional or reformed medical teaching curricula.

\footnotetext{
* DRG - Geschäftsführung
}

Key Points:

- Radiology is an integral and important part of medical education.

- The German Society of Radiology (DRG) developed a model curriculum for teaching radiology at German Medical Faculties to help students develop the ability to make medical decisions based on scientific knowledge and act accordingly.

- This curriculum can be used for individual curricular development at medical departments. It is divided into two modules with several chapters.

Citation Format:

- Ertl-Wagner B, Barkhausen J, Mahnken AH et al. White Paper: Radiological Curriculum for Undergraduate Medical Education in Germany. Fortschr Röntgenstr 2016; 188: 1017-1023

\section{Zusammenfassung \\ $\nabla$}

Ziel: Die Radiologie hat als Fachgebiet eine hohe Relevanz innerhalb des Medizinstudiums, von der vorklinischen Lehre bis hin zum praktischen Jahr. Als Querschnittfach hat die Radiologie Bezüge zu den Inhalten nahezu aller anderen Fächer. Es ist daher wichtig, eine gemeinsame inhaltliche Grundlage für die studentische Lehre in der Radiologie zu etablieren.

Material und Methoden: Die Deutsche Röntgengesellschaft (DRG) hat ein radiologisches ModellCurriculum für das Medizinstudium entwickelt, das in diesem Artikel dargestellt werden soll; auch auf der europäischen Ebene gibt es ein Curriculum für die studentische Lehre (U-Level Curriculum der European Society of Radiology). Den Studierenden sollen im Rahmen eines modularen Konzeptes wichtige radiologische Kernkompetenzen in Bezug auf Wissensinhalte, Fähigkeiten und Fertigkeiten sowie Grundlagen des wissenschaftlichen Arbeitens vermittelt werden. 
Ergebnisse: Das Curriculum ist in zwei aufeinander aufbauende Module mit jeweils mehreren Unterkapiteln aufgeteilt: Im Modul 1 werden die Grundprinzipien der Strahlenbiologie, des Strahlenschutzes und der Gerätetechnik vermittelt. Auch Risiken und Nebenwirkungen der verwendeten Verfahren und Kontrastmittel sind ein wichtiger Teil von Modul 1. Die Herangehensweise in diesem Modul ist modalitätenorientiert. Im Modul 2 werden die radiologische Diagnostik und interventionell-radiologische Verfahren für spezifische Krankheitsbilder vermittelt. Die Herangehensweise ist in diesem Modul organsystemorientiert.

Schlussfolgerung: Das Modell-Curriculum wird als lebendiges Dokument verstanden, das jederzeit Ergänzungen und/oder Änderungen finden kann und soll. Das Curriculum kann als Grundlage für die individuelle Lehrplanentwicklung an den Medizinischen Fakultäten herangezogen und sowohl in traditionelle als auch in Reformstudiengänge integriert werden.

\section{Introduction}

$\nabla$

Radiology is a highly relevant part of undergraduate medical education. From preclinical studies of cross sectional anatomy and the fundamental principles of radiation biology, radiation protection and imaging technology to the diagnosis and interventional radiological treatment of specific diseases, radiology accompanies students through their medical education and helps to promote the idea of unity of teaching and research. Comprehensive radiological training during medical education provides students with experience in Imaging Sciences, and research-based learning helps students to develop the ability to make medical decisions based on new scientific evidence and act accordingly. In 2014, the German Council of Science and Humanities published recommendations regarding the further development of medical education in Germany [1]. These recommendations are based on an evaluation of model medical teaching curricula and include recommendations regarding the structure of future medical education, the strengthening of scientific competencies, the focusing of course content, and the coordination of teaching and examination formats [1].

In a cooperative project of the German Medical Faculty Association and the German Association for Medical Education, a national competency-based catalogue of learning objectives for undergraduate medical education was developed. This catalogue was adopted at the 76th general assembly of the German Medical Faculty Association on 6/4/2015 in Kiel and was then published on-line [2]. This catalogue of learning objectives includes the different competencies to be taught to medical students [3]. In Switzerland, the Swiss Catalog of Learning Objectives for Undergraduate Medical Training (SCLO) was developed as part of a mandate of the Joint Commission of the Swiss Medical Schools [4].

As a result of the recommendations of the German Council of Science and Humanities and the national competency-based catalog of learning objectives for undergraduate medical education, the content of medical teaching curricula is increasingly becoming a topic of interest, also for scientific professional societies. In Europe, the European Society of Radiology developed a curriculum for teaching medical students in radiology (undergraduate-level curriculum, U-level curriculum) [5].
In analogy to this European U-level curriculum, the following German curriculum which is meant as a living document that can and should be revised at any time is divided into two modules:

- Module 1: This module includes the basic principles of radiation biology, radiation protection, and imaging technology. The risks and side effects of the methods and contrast agents are also an important part of module 1 . This module is modality-oriented.

> Module 2: This module includes radiological diagnosis and interventional radiological methods for various diseases. Module 2 is organ system-oriented.

The learning objectives of the individual modules and their chapters are divided into "knowledge" and "skills and abilities" contents. Skills and abilities are to be acquired during course, sub internships and elective rotations in which students work with images and patients under teacher guidance. Communicative skills and abilities are also important in this regard and should be taught in practical radiology courses.

Both modules and their chapters can be adapted to traditional as well as reformed medical teaching curricula. There are also numerous connections to preclinical training. Therefore, for example, knowledge of anatomy in projection radiography and cross-sectional imaging as defined in the chapters of module R-2 can be effectively taught in preclinical courses or with a longitudinal approach. Good experiences regarding such an interdisciplinary approach in preclinical education, particularly in relation to radiological anatomy, have already been reported [6-9]. The present curriculum with its modular structure can also be effectively used for interdisciplinary teaching approaches. A survey of chairpersons in radiology in Germany showed a high acceptance rate for integrative teaching concepts in radiology [10].

The principles of problem-based learning and other modern teaching concepts, such as the "flipped classroom" technique, are highly suitable for radiological teaching during medical education. The present curriculum with its modular structure can also be effectively used for this purpose [11-13].

\section{Radiology module 1 (R-1)}

$\nabla$

\section{R-1.1 Principles of radiation biology and radiation} protection

Knowledge

Knowledge of the properties of ionizing radiation and radioactive decay

- Understanding of the manner in which X-rays are generated and how they interact with matter

- Understanding of the stochastic, deterministic and teratogenic effects of radiation

- Understanding of the effects of ionizing radiation on cells, tissue and organs

- Knowledge of repair mechanisms after radiation

- Basic knowledge of radiation exposure from natural sources of radiation

- Knowledge of the risks of using radiation in medicine compared to natural radiation exposure

> Basic knowledge of the most important dose measures and their units 
Knowledge of dosimetry methods and relevant dose limits

> Comprehensive understanding of the As Low As Reasonably Achievable (ALARA) principle

> Understanding of the factors affecting image quality and dose in radiology

- Understanding of the methods for reducing radiation exposure for patients

- Basic knowledge of radiation protection for personnel

Skills and abilities

- Ability to apply principles of radiation biology and radiation physics for the selection of the most suitable imaging methods for various clinical situations

- Ability to use the correct designations and measurement units to describe radiation exposure

- Ability to integrate the ALARA principle into the clinical routine

- Ability to apply suitable radiation protection measures in diagnostic and interventional radiology

- Ability to prevent unnecessary radiation exposure by selecting the most suitable imaging modality and technology

- Ability to counsel patients, family members, and employees in relation to the benefits and radiation-related risks of a planned examination or intervention

\section{R-1.2 Radiology methods}

Knowledge

- Understanding of the value of radiographic examinations for various organ systems and indications

- Knowledge of the components and mode of operation of an X-ray tube

- Understanding of the manner in which X-rays are generated

- Knowledge of the tissue properties that affect imaging in radiographic examination and fluoroscopy

- Basic knowledge of the principles and most important indications for fluoroscopy

- Understanding of the factors affecting image quality and dose in radiographic examinations and fluoroscopy

- Basic knowledge of the principles of radiography of soft tissue/mammography

Knowledge of the positioning of patients for radiographic examinations

- Comprehensive knowledge of the normal anatomy of various organs and structures on radiographic images

- Understanding of the value of computed tomography (CT) for various organ systems and indications

- Understanding of the physical principles of CT imaging

- Knowledge of the tissue properties that affect CT imaging

- Understanding of Hounsfield units and their scaling

- Knowledge of normal attenuation values in Hounsfield units for important tissue and selected, various pathologies (e.g. bleeding, calcifications)

- Knowledge of normal cross-sectional anatomy in CT

- Understanding of the value of magnetic resonance imaging (MRI) for various organ systems and indications

- Basic understanding of the principles of MRI

- Knowledge of the tissue properties that affect MRI

- Basic knowledge of the most important MRI sequences

- Knowledge of the absolute and relative contraindications for MRI
- Understanding of the safety requirements in MRI in relation to patients and employees

- Knowledge of normal cross-sectional anatomy in MRI

- Understanding of the value of ultrasound for various organ systems and indications

- Basic understanding of the principles of ultrasound imaging

- Knowledge of the tissue properties that affect ultrasound imaging

- Knowledge of transmission frequencies and the different types of ultrasound probes

- Basic knowledge of the principles of the Doppler effect

- Knowledge of normal anatomy in ultrasound

- Basic knowledge of the principles of digital subtraction angiography (DSA)

- Basic knowledge of the different types and techniques of image-guided interventions

- Basic knowledge of IT infrastructure in radiology with Picture Archiving and Communication Systems (PACS) and Radiological Information Systems (RIS)

\section{Skills and abilities}

- Ability to identify and describe the acquisition method used for a presented imaging study (e.g. p. a. radiography of the thorax, lung CT, etc.)

- Ability to detect insufficient image quality in radiographic examinations, fluoroscopic examinations, CT, MRI, and ultrasound including angiography.

- Ability to measure Hounsfield units in CT and identify corresponding tissue properties

- Ability to identify and name the most frequently used MRI sequences and planes (e.g. sagittal T2-weighted sequence, etc.)

- Ability to reliably define and name the relevant normal anatomical structures in X-ray examinations, fluoroscopic examinations, CT, MRI, and ultrasound

- Ability to communicate the benefits and risks of the most important radiological examinations (including radiographic examinations, fluoroscopic examinations, CT, MRI, ultrasound) to patients and their family members

\section{R-1.3 Contrast agents in radiology}

\section{Knowledge}

- Knowledge of indications for the use of radiographic contrast agents for examining various organs/organ systems

- Knowledge of indications for the use of iodine-containing contrast agents for examining various organs/organ systems in CT.

- Understanding of the risks and side effects of frequently used iodine-containing contrast agents for radiographic examinations, fluoroscopic examinations, and CT

- Knowledge of the indications for the use of MRI contrast agents for examining various organs/organ systems

- Understanding of the risks and side effects of frequently used MRI contrast agents

- Basic knowledge of ultrasound contrast agents

- Understanding of acquisition times after bolus administration of contrast agent and their relevance for a particular issue

- Knowledge of the risk factors for contrast agent-induced nephropathy and the measures for reducing this risk 
Basic knowledge of nephrogenic systemic fibrosis (NSF) and the measures for reducing the risk of NSF

Skills and abilities

- Ability to identify whether a CT or MRI examination is contrast-enhanced

- Ability to identify the various types of contrast-enhanced fluoroscopic examinations

- Ability to determine (with supervision) when contrast administration is indicated for a particular clinical question

- Ability to communicate the benefits and risks of contrast administration in the most important radiological examinations (including radiographic examinations, fluoroscopic examinations, CT, MRI, and ultrasound) to patients and their family members

\section{Module R-2}

$\nabla$

\section{R-2.1 Abdominal radiology}

Knowledge

- Knowledge of the normal anatomy of the most important structures of the abdominal organs and the gastrointestinal tract in radiographic examinations, fluoroscopic examinations, CT, ultrasound, and MRI

- Knowledge of the typical radiological findings in the case of acute abdomen, including perforation, bleeding, inflammation/infection, obstruction, and ischemia in radiographic examinations, CT, and ultrasound

- Knowledge of the typical radiological findings in colorectal tumors, diverticulitis, and inflammatory bowel diseases (including Crohn's disease and ulcerative colitis)

- Knowledge of the typical radiological findings in primary and secondary tumors of the abdominal organs

Skills and abilities

- Ability to identify the normal abdominal organs and the parts of the gastrointestinal tract in radiographic examinations, fluoroscopic examinations, CT, ultrasound, and MRI

- Ability to identify signs of obstruction on radiographic images of the abdomen

- Ability to identify signs of gastrointestinal perforation on radiographic images of the abdomen

- Ability to perform a basic ultrasound examination of the upper abdomen under supervision

- Ability to communicate the procedure, benefits and risks of different diagnostic and interventional radiological procedures of the abdomen (e. g. abscess drainage, embolization in the case of bleeding, minimally invasive treatment of malignant tumors of the liver) to patients and their family members

- Ability to communicate the results of radiological examinations of the abdomen to patients and their family members

\section{R-2.2 Ear, nose, and throat radiology}

Knowledge

- Knowledge of the most important structures of the normal anatomy of the head and neck region in radiographic examinations, fluoroscopic examinations, ultrasound, CT and MRI

- Basic knowledge of the most common radiological findings in traumatic and inflammatory diseases of the base of the skull, nose, paranasal sinuses, oral cavity, pharynx, larynx, and thyroid

- Basic knowledge of the typical morphological presentation of common tumors of the base of the skull, nose, paranasal sinuses, oral cavity, pharynx, larynx, and thyroid

\section{Skills and abilities}

- Ability to define the most important normal structures of the head and neck region in radiographic examinations, fluoroscopic examinations, ultrasound, CT and MRI

- Ability to communicate the procedure, benefits and risks of different radiological examinations of the head and neck region to patients and their family members

- Ability to communicate the results of radiological examinations of the head and neck region to patients and their family members

\section{R-2.3 Interventional radiology}

Knowledge

- Understanding of the normal anatomy of the arterial and venous vascular system and its significance for interventional radiology

- Knowledge of the typical access routes for common endovascular treatment methods in interventional radiology

- Understanding of the typical access routes for imageguided biopsy, drainage placement, and tumor ablation

- Understanding of the benefits and risks of common interventional radiological methods

- Knowledge of the procedure in emergency situations in interventional radiology

- Understanding of the differential indications between interventional radiological treatment, operation and conventional treatment strategies in select diseases (e.g. stage-dependent in the treatment of peripheral arterial occlusive disease, treatment of hepatocellular carcinomas)

\section{Skills and abilities}

- Ability to identify physiological arterial and venous vascular structures on digital subtraction angiography

- Ability to explain the procedure used in different radiological interventions to patients and their family members

- Ability to weigh the benefits and risks of various radiological interventions

\section{R-2.4 Cardiovascular radiology}

Knowledge

- Knowledge of the normal anatomy of the heart and the vessels in radiographic examinations (Doppler/duplex) ultrasound, $\mathrm{CT}$, and MRI

- Basic knowledge of the visualization of congenital and acquired heart defects on chest X-ray

- Differentiation of the radiological presentation and the causes of heart enlargement, including valve diseases and pericardial diseases 
Knowledge of the typical presentation of signs of cardiac decompensation on chest X-ray

- Knowledge of the radiological visualization of vascular occlusions, stenoses, and thromboses

- Understanding of the diagnostic procedure in ischemic heart diseases

- Knowledge of the normal dimensions of the aorta and the classification of aortic aneurysms and dissections

Skills and abilities

- Ability to reliably delimit normal anatomical structures of the heart and great vessels on chest X-ray

$\checkmark$ Ability to identify and name the different types of cardiomegaly on chest X-ray

> Ability to identify vascular occlusions, stenoses, and thromboses in Doppler/duplex ultrasound, CT, MRI, and angiography

- Ability to a place peripheral venous access

- Ability to communicate the procedure, benefits and risks of various diagnostic and interventional radiological methods for examining the cardiovascular system to patients and their family members

> Ability to communicate the results of radiological examinations of the cardiovascular system to patients and their family members

\section{R-2.5 Pediatric radiology}

Knowledge

> Knowledge of the most important structures of the normal anatomy in children and changes thereto over the course of childhood and adolescence in radiographic examinations, ultrasound, CT, and MRI

> Understanding of the diagnostic value of and the indications for ultrasound, radiographic, CT, and MRI examinations in children and adolescents

- Understanding of the increased sensitivity of children and adolescents to ionizing radiation and knowledge of the special importance of radiation protection in children

> Basic knowledge of the typical radiological findings in accidental and non-accidental injuries in children

- Basic knowledge of the typical radiological findings of the most common diseases in children and adolescents

Skills and abilities

- Ability to define and name the most important normal anatomical structures on radiographic images of the chest and skeleton in children and adolescents

> Ability to identify and name the radiological signs of fractures in children and adolescents

> Ability to perform a basic abdominal ultrasound examination under supervision in children and adolescents

- Ability to establish a child-friendly examination and communication environment

- Ability to communicate the procedure, benefits and risks of radiological examination to pediatric patients and their family members in an age-appropriate manner

- Ability to communicate and interpret findings of radiological examinations for pediatric patients and their family members in an age-appropriate manner

\section{R-2.6 Breast imaging and gynecological radiology}

Knowledge

- Knowledge of normal anatomy of the female breast and axilla and changes thereto in the course of development and aging

- Knowledge of the principles of digital mammography

- Basic knowledge of breast ultrasound and breast MRI as an additive procedure

> Basic knowledge of the morphological presentation of common benign and malignant diseases of the breast

- Knowledge of the normal anatomy of the most important structures of the female pelvis in ultrasound, CT, and MRI

- Basic understanding of changes in the organs of the female pelvis over a lifetime

- Basic knowledge of typical radiological findings of tumors of the female pelvis

- Understanding of the typical radiological findings in common diseases in pregnancy and puerperium

Knowledge of radiation protection methods for the female pelvis in $\mathrm{CT}$ and radiographic examinations

Skills and abilities

- Ability to identify and name the type of projection of mammographic images

- Ability to define and name the normal anatomical structures in mammography

- Ability to identify and name typical pathological findings in mammography (under supervision)

- Ability to communicate benefits, risks, and basic technical aspects of mammography to patients and their family members

- Ability to perform transabdominal ultrasound scan of the female pelvis under supervision for the purpose of orientation

- Ability to identify the most important physiological structures of the female pelvis in ultrasound, CT, and MRI

- Ability to communicate the procedure, benefits and risks of different radiological methods for examining the female pelvis to patients and their family members

- Ability to communicate the results of radiological examinations of the female pelvis to patients and their family members

- Ability to select the most suitable radiological method for examining pregnant patients for various clinical indications

\section{R-2.7 Musculoskeletal radiology}

Knowledge

- Knowledge of the normal anatomy of the most important structures of the musculoskeletal system in radiographic examinations, CT, and MRI

- Knowledge of the typical radiology findings in traumatic skeletal changes (e.g. fractures, luxations)

- Understanding of the typical radiology findings in degenerative skeletal changes (e.g. osteoarthritis)

Knowledge of the typical radiology findings in infections and inflammation, metabolic diseases and common bone tumors 


\section{Skills and abilities}

- Ability to locate and name the most important anatomical structures of the musculoskeletal system in radiographic examinations, CT, and MRI

- Ability to identify and differentiate the most common fractures on radiographic images of the skeletal system (e.g. Colles fracture)

- Ability to communicate the procedure, benefits and risks of different radiological examinations of the musculoskeletal system to patients and their family members

- Ability to communicate the results of radiological examinations of the musculoskeletal system to patients and their family members

\section{R-2.8 Neuroradiology}

Knowledge

- Knowledge of the normal anatomy of the most important structures of the brain, skull, skull base, spine and spinal cord in CT and MRI

- Understanding of the typical radiological changes in ischemic and hemorrhagic stroke in CT and MRI

- Knowledge of the typical radiological findings in injuries to the brain and spine in CT and MRI

- Knowledge of the typical radiological findings in injuries to the white matter and neurodegenerative diseases in CT and MRI

- Knowledge of the typical radiological findings in common tumors of the brain and spine

- Knowledge of the typical radiological findings in inflammation of the brain and meninges

Skills and abilities

- Ability to define and name the most important normal anatomical structures of the brain and spine

- Ability to identify and differentiate the different types of intracranial bleeding in CT and MRI

- Ability to identify the imaging features of spinal cord compression

- Ability to communicate the procedure, benefits and risks of different neuroradiological examinations to patients and their family members

- Ability to communicate the results of neuroradiological examinations to patients and their family members

\section{R-2.9 Thoracic radiology}

\section{Knowledge}

- Knowledge of the normal anatomy of the most important structures of respiratory tracts and lungs, the heart, large vessels, the mediastinum, and the thoracic wall on radiographic and CT examinations of the chest

- Knowledge of the imaging features of common devices, tubes and lines on radiographic examinations of the chest, including endotracheal tubes, central venous catheters, gastric tubes, pacemakers, and defibrillators

- Knowledge of the typical imaging findings of pleural effusion in radiographic examinations of the chest and its most common causes

- Knowledge of the typical imaging features and clinical significance of a pneumothorax and a tension pneumothorax in radiographic examinations of the chest
- Knowledge of the presentation of typical and atypical pneumonic infiltrates in radiographic examinations of the chest and in CT

- Knowledge of the typical presentation of emphysema in radiographic and CT examinations of the chest

- Knowledge of the typical presentation of bronchiogenic carcinomas and pulmonary metastases in radiographic and CT examinations of the chest

- Knowledge of the presentation of various mediastinal masses in radiographic and CT examinations of the chest

\section{Skills and abilities}

- The ability to define and name the following structures in posterior-anterior (p.a.) and lateral radiographic examinations of the thorax: Fissures and lobar boundaries of the lung, trachea, main bronchi, atria and ventricles of the right and left heart, pulmonary arteries, aorta, mediastinal parts and diaphragm

- Ability to reliably identify correct and incorrect positions of tubes, lines and devices in radiographic examinations of the chest: Endotracheal tube, central venous catheter, gastric tube, pacemaker, and defibrillator

- Ability to identify and describe the following signs in radiographic examinations of the thorax: Air bronchogram, air crescent sign, deep sulcus sign

- The ability to identify and describe pneumonic infiltrates, emphysema, masses of the lung and mediastinum, pleural effusions, and pneumothorax on radiographic images of the chest

- Ability to reliably identify a tension pneumothorax on radiographic images of the chest

- Ability to communicate the procedure, benefits and risks of different diagnostic and interventional (e.g. pleural puncture, thorax drainage) radiological procedures for examining the thorax to patients and their family members

- Ability to communicate the results of radiological examinations of the thorax to patients and their family members

\section{R-2.10 Urogenital radiology}

Knowledge

- Knowledge of the normal anatomy of the kidneys, retroperitoneum, the ureters, the bladder, the urethra, and the genital tract on ultrasound, CT, and MRI

- Understanding of contrast agent management in renal failure

- Knowledge of the typical radiological findings of the most common diseases of the kidneys and the efferent urinary tract

- Knowledge of the typical radiological findings of the most common diseases of the prostate and the testicles

\section{Skills and abilities}

- Ability to define and name the most important anatomical structures of the urogenital system in radiographic examinations, CT, and MRI

- Ability to identify the typical radiological signs of a urinary tract obstruction in ultrasound, CT, and MRI

- Ability to perform an ultrasound examination of the kidneys and the pelvis under supervision for the purpose of orientation 
- Ability to communicate the procedure, benefits and risks of different radiological examinations of the urogenital tract to patients and their family members

- Ability to communicate the results of radiological examinations of the urogenital tract to patients and their family members

\section{Affiliations}

1 Institute of Clinical Radiology, Ludwig Maximilians University - Großhadern Campus, Munich, Germany

2 Department of Radiology and Nuclear Medicine, University Hopsital Schleswig Holstein Luebeck Campus, Germany

3 Diagnostic and Interventional Radiology, Philipps University, Marburg, Germany

4 Paediatric Radiology, Institute for Diagnostic and Interventional Radiology, Jena, Germany

5 Radiological Institute, University Hospital Erlangen, Germany

6 Institute of Diagnostic and Interventional Radiology, Hannover Medical School, Germany

7 Clinic and Policlinic for Diagnostic and Interventional Radiology, Leipzig, Germany

\section{References}

1 http://www.wissenschaftsrat.de/download/archiv/4017-14.pdf; last accessed August 1, 2016

2 http://www.nklm.de/files/nklm_final_2015-07-03.pdf; last accessed August 1, 2016
3 Hautz SC, Hautz WE, Keller $N$ et al. The scholar role in the National Competence Based Catalogues of Learning Objectives for Undergraduate Medical Education (NKLM) compared to other international frameworks. Ger Med Sci 2015; 13: Doc20

4 http://sclo.smifk.ch/sclo2008/fulltext; last accessed August 2, 2016

5 https://www.myesr.org/html/img/pool/ESR_2014_ESR-EuropeanTrainingCurriculum_U-LEVEL.pdf; last accessed August 1, 2016

6 Schober A, Pieper CC, Schmidt R et al. "Anatomy and imaging": 10 years of experience with an interdisciplinary teaching project in preclinical medical education - from an elective to a curricular course. Fortschr Röntgenstr 2014; 186: 458-465

7 Dettmer S, Schmiedl A, Meyer S et al. Radiological anatomy - evaluation of integrative education in radiology. Fortschr Röntgenstr 2013; 185: $838-843$

8 Phillips AW, Smith SG, Straus CM. The role of radiology in preclinical anatomy: a critical review of the past, present, and future. Acad Radiol 2013; 20: 297-304

9 Miles KA. Diagnostic imaging in undergraduate medical education: an expanding role. Clin Radiol 2005; 60: $742-745$

10 Dettmer S, Weidemann J, Fischer $V$ et al. Integrative teaching in radiology - a survey. Fortschr Röntgenstr 2015; 187: 260-268

11 Thurley P, Dennick R. Problem-based learning and radiology. Clin Radiol 2008; 63: 623-628

12 Collins J. Teacher or educational scholar? They aren't the same. J Am Coll Radiol 2004; 1: 135-139

13 Morton DA, Colbert-Getz JM. Measuring the impact of the flipped anatomy classroom: The importance of categorizing an assessment by Bloom's taxonomy. AnatSci Educ; DOI: 10.1002/ase.1635. PMID: 27427860 